\title{
Recent trends of research in open and distance education in India
}

Recent trends of research in education

Centre for Internal Quality Assurance, Indira Gandhi National Open University, New Delhi, India

Bijayalaxmi Mishra

Research Unit, Indira Gandhi National Open University, New Delhi, India

Dev Kant Rao

Academic Coordination Division, Indira Gandhi National Open University, New Delhi, India

Navita Abrol

Centre for Internal Quality Assurance, Indira Gandhi National Open University, New Delhi, India

Vandana Varma

Academic Coordination Division, Indira Gandhi National Open University,

New Delhi, India, and

Bharat Bhushan

Student Service Centre, Indira Gandhi National Open University, New Delhi, India

\begin{abstract}
Purpose - The purpose of this paper was to analyse the research trends on the Indian Open and Distance Education (ODE) system as reflected in the articles published in the prominent journals of distance education across the world.

Design/methodology/approach - A study was undertaken to review the research articles on ODE in India published in 11 prominent peer-reviewed journals of distance education during the period 2010-2019. Content analysis was done to find out areas of research undertaken in the ODE of India based on a validated classification of research areas; types of research studies conducted; and authorship and publication patterns. Findings - Out of a total of 2,571 articles published in 11 selected journals, only $191(7.42 \%)$ pertained to ODE in India. The majority of these 191 articles $(68.42 \%)$ were published in Indian journals. The Indian and Asian journals together accounted for $93.55 \%$ of total articles. Globally, the share of articles on the Indian ODE system was significantly low ranging between 4.27 and a maximum of $10.77 \%$, which was much below expectations from a country having the maximum number of ODE learners in the world. Results further revealed that $63 \%$ of the contributors to research on ODE in India were affiliated to Indira Gandhi National Open University.

Research limitations/implications - The limitation of this study was only analysing the research articles published in journals of distance education and other types of articles, namely, book reviews, editorials, field notes and workshop reports were excluded from the analysis.

Practical implications - The study is intended to help researchers, policymakers, and open and distance education institutions to draw a roadmap for the promotion and conduct of system-based research, which would be vital for strengthening the system.
\end{abstract}

(C) Manjulika Srivastava, Bijayalaxmi Mishra, Dev Kant Rao, Navita Abrol, Vandana Varma and Bharat Bhushan. Published in Asian Association of Open Universities Journal. Published by Emerald Publishing Limited. This article is published under the Creative Commons Attribution (CC BY 4.0) licence. Anyone may reproduce, distribute, translate and create derivative works of this article (for both commercial and non-commercial purposes), subject to full attribution to the original publication and authors. The full terms of this licence may be seen at http://creativecommons.org/licences/by/4.0/legalcode

Received 6 July 2020 Revised 25 August 2020 Accepted 27 August 2020 
AAOUJ

15,2

Social implications - The quantum of research is not proportionate to the number of faculty members working in the ODE system of India and the large number of learners that it serves, which is a matter of concern. For any system to grow its periodic systemic review is essential. The research outcomes need to be ploughed back into the system for its betterment.

Originality/value - The study is original. There is no such study undertaken till date. This study will be extremely useful to researchers, as the gaps in distance education research which are yet to be addressed, have been identified by the authors.

Keywords Open and distance education, Content analysis, Research trends, Research areas

Paper type Literature review

\section{Introduction}

The seed of distance education, sown in the middle of the 19th century, blossomed a century later, for the reason that many countries had adopted it post-Second World War. Decolonization led many nations on the trail of expanding their educational base. The opportunity of access, affordability and convenience offered by the Distance Education system made it the preferred choice for them. The foundation of the British Open University in 1969 was a seminal moment in the history of distance education and its subsequent success had a rippling effect across the world (Srivastava, 2012). The Open University system ushered in "radical deviations from the traditions of University Education" by introducing large scale industrialization of education (Peters, 1983). By this time, a century's worth research had gone into the growth and development of the Distance Education system. On the basis of review of the research conducted in the field of distance education during 1970s and 1980s, "the dearth of research on Distance Education was replaced by a wealth of studies" (Holmberg, 1986). More than 300 studies on distance education could be listed that had been published mostly in the latter half of the 1970s and the beginning of the 1980s. Interestingly these research studies had their base in the knowledge and theory already developed in other disciplines such as Education, Philosophy, Psychology, Sociology, History and Economics. Such efforts that lead to emergence of new knowledge, can be ascribed to the beginnings of a new discipline, that of distance education (Holmberg, 1986).

The first journal to publish research specifically in the field of distance education was "Distance Education" published by the Australian and South Pacific External Studies Association (ASPESA) - the predecessor of the Open and Distance Learning Association of Australia (ODLAA), founded in 1973 for professional development of distance educators working in Australia, New Zealand, Papua New Guinea and the member countries of the University of the South Pacific (Bewley, 2008). It was followed, almost simultaneously in the 1980s, by launch of three more international journals, namely, "Open Learning" in 1986 (renamed as "Open Learning: The Journal of Open Distance and e-Learning"); the "Journal of Distance Education" in 1986 (renamed as "The International Journal of E-Learning and Distance Education" in 2014) and the "American Journal of Distance Education" in 1987. These journals played a pivotal role in establishing distance education as a separate discipline in the scholarly world (Moore, 2016). The distance education as a discipline thereafter never looked back and a number of good quality journals were introduced centred around various facades of open and distance education (ODE) which has resulted in an exponential growth in the literature on ODE.

India, with 15 Open Universities (OUs), more than a 100 Directorates of Distance Education (DDEs) which are functioning under Dual Mode Universities (DMUs), and more than 1.7 million learners pursuing their higher education through this mode (UGC, 2019), has one of the largest ODE systems in the world. For any system to grow and maintain its quality and standards, its periodic review is essential. Being a dynamic technology-assisted system, ODE keeps on evolving with the adoption of new technological interventions, and needs to be regularly evaluated to ensure the efficacy and effectiveness of the system. The journals 
published in the field of distance education are providing the platform to distance educators/ practitioners, teachers and students working/studying at these institutions to publish scholarly work in the field of ODE and at the same time disseminate their scholarship and extension of their research to the rest of the world. From an Indian perspective, the Indira Gandhi National Open University (IGNOU) took the lead and started the "Indian Journal of Open Learning (IJOL)" in 1992 for promoting professional development of its teachers, academics and students, including their counterparts working in other OUs and DDEs. The launch of IJOL was major milestone in the journey of research in distance education in India. Along with launching the journal, IGNOU also played a major role in strengthening the concept of system-based research by funding ODE faculty members working at IGNOU, other OUs and DDEs to undertake research on various facets of ODE. The erstwhile Distance Education Council (DEC) under its research project scheme provided funding to nearly 100 research projects to the tune of about 10m rupees (Srivastava, 2012).

The University Grants Commission (Open and Distance Learning) Regulations, 2017, which regulates all ODE Institutions in India, lays major emphasis on research by faculty members (Government of India, 2017). Research has also been made mandatory for all teachers and academics working in Higher Education Institutions (HEIs) including universities, as it acts as an important indicator for evaluating their academic performance in appointments and career advancement (Government of India, 2010, 2018). Promoting and undertaking quality research is as essential for Indian universities, as it is for other universities, to achieve higher global rankings. To encourage system-based research, Research, Innovations and Extension, forms a major criterion for assessing and grading an OU or a DDE working under a DMU for accreditation by the National Assessment and Accreditation Council (NAAC). In the case of an OU, this criterion is assigned $20 \%$ of the overall weightage. NAAC evaluates an OU by assessing the contribution of its teachers and other academic staff members in research for the development of the ODE system; and other disciplines to contribute to new knowledge. Therefore, OUs are expected to give due consideration to research and provide a conducive and enabling environment in terms of infrastructure, human resource and finance, etc. to different stakeholders. Research, hence, needs to be facilitated by a suitable policy framework. This criterion seeks information on the policies, practices of research and development at a university (NAAC, 2019). Also, it is the quality of research which represents the academic image of not just the individual carrying out research, but also the institution to which the researcher belongs.

\section{Objectives}

It is in the above-mentioned context, that this research study was undertaken by our team with the dual purpose, first, to review the quantum of research done in the area of $O D E$ in India, and secondly, to find out the status of system-based research in the country in the light of the above developments. The key objectives of the study were as follows:

(1) To assess the quantum of research done on ODE at higher education level in India;

(2) To explore the trends of areas research in the ODE;

(3) To categorize research in ODE from the point of view of the research methods used along with the institutional affiliation of the researchers undertaking research in ODE;

(4) To find out the potential areas and the hitherto neglected areas of research in ODE in India and

(5) To suggest measures to improve the standards and encourage system-based research. 


\section{AAOUJ}

15,2

266

\section{Literature review}

Regular attempts have been made to review and classify research on distance education across the world, with a few isolated attempts on research trends on ODE in India. The first major study that focussed on the research articles published on Correspondence Education, prevalent in India since 1960s, was undertaken by Gupta and Arun in 1986. In their study Gupta and Arun categorized the research articles into 11 areas and highlighted that the focus of research was on the concept and definitions, course development, use of media and technology, student evaluation, student enrolment and dropout, the problems that ails the system and its future. They pointed out that research was still at the nascent stage since most of the articles expressed the views of the authors and not based on empirical study (Gupta and Arun, 1986).

The next major study was undertaken by Panda (1992), which was far more comprehensive and exhaustive, covering 142 research articles on ODE in India both published and unpublished and MPhil and $\mathrm{PhD}$ dissertations. The research studies across selected articles were classified under nine research themes, with a clear demarcation of research under correspondence education and ODE and further placed in the structural framework of input, process and output model. The themes shortlisted by Panda covered almost all facets of ODE, namely, concept and growth; course design and development; instruction; learner support; media and technology; learners and learning; policy and management; evaluation; economics and staff development. Through his study, Panda (1992) brought out that the majority of the research articles were descriptive surveys with not so structured methodological designs and that there was a lack of holistic studies to arrive at any generalizations. He highlighted numerous constraints for research in distance education which were lack of funding, staff members and institutional policy. This study evolved into a book covering 152 research studies on ODE in India with detailed annotations on 88 research studies with the authors expressing the same concerns as pointed out by Panda in 1992 (Panda et al., 1996).

The study by Panda was followed by Mishra (1997), who undertook an elaborate study across 361 articles published in four leading distance education journals. He analysed the nature of research published in these journals; research methods used; average number of references per contribution; contributions without references; authorship pattern; the most frequent contributors and their country of origin. The study by Mishra revealed that research in distance education was majorly based on survey method, mostly descriptive and lacked methodological rigour. He also found that single authors were contributing to majority of the research articles and that more than $80 \%$ papers originated from the UK, USA, Canada and India, which interestingly coincides with our findings.

On the completion of 10 years of IJOL, Mishra (2002) undertook another study. This time, he did a comprehensive review of all the research articles published in the IJOL since its inception covering the first decade of its existence. In his analysis pointed out that it was the IGNOU that provided it strong institutional support to the journal because of which it emerged as a good platform for exchange of ideas and dissemination of information for both Indian and foreign authors. Mishra's findings, however, matched with his own as well as other researcher's findings that the research methods used in the articles published in IJOL were mostly descriptive, followed by survey method and conceptual analysis with the majority of researchers using questionnaire and psychometric scale and lack of methodological rigour. Another finding that the first author's country of origin being India $(66 \%)$ and that even within India, majority of articles originated from Delhi, again coincides with our findings. Thereafter, Tripathi and Kanungo (2010) made an attempt to profile the type of research including citation analysis, authorship pattern, popular areas of research and research methodologies used, published in IJOL from 2000 to 2009 covering 204 articles authored by 335 contributors. In a recently published article, Satyanarayana and Mantha (2018) 
had summarized all the review studies undertaken in a chronological manner up to 2006 only. In any case, in the study by Mishra of 2002 IJOL emerged as one of the most scholarly publications of ODE in India.

We did not come across any other such major review of research in ODE in India, justifying the need for taking up the review of literature published on ODE system of India and find out the gaps in the existing research, so as to suggest a way forward.
Recent trends of research in education

\section{Methodology}

This research study was undertaken to explore the research on ODE conducted in India and abroad and published in prominent journals of distance education during the last decade from 2010 to 2019 by mapping the research contribution of Indian and foreign researchers working at HEIs in India and abroad. The study was based on an extensive review of articles on "Open and Distance Education in India", published in 11 prominent journals in the field of distance education, three of which were published within India while rest eight were published abroad (Table 1). Only those Indian journals were included in the study which featured in the UGC Consortium for Academic and Research Ethics (UGC CARE) list.

Based on data mining of 2,571 articles published across 104 volumes and 306 issues and published between 2010 and 2019 in 11 selected journals; 191 articles that focussed on research in ODE in India, were shortlisted. The content of these 191 articles was thoroughly analysed by our team of six raters or coders for classification of the areas of research, the types of research methods used by the researchers including their institutional affiliations, authorship pattern, gender-wise distribution and a content analysis of research studies conducted. A tool was prepared for data collection covering the following parameters: volume number, issue number; total number of articles published in each issue; article on ODE in India which was further classified under the following: research area, research method used; institutional affiliation of the author(s) and gender of the first author, The collected data were subjected to quantitative and descriptive analysis for reporting the outcomes of the study and graphical presentations to explicitly highlight the findings.

\section{Inter-rater reliability between coders}

In order to ensure the reliability of data and rating methods, the authors conducted an interrater reliability test, by conducting a sample analysis across 30 randomly selected articles. In order to ensure minimum variation, the coding was done at two levels, first all the six authors (coders) coded the articles distributed amongst them and second, once the coding at individual levels was completed, all the six coders were divided into two groups of three coders each, who again checked the correctness of coding. Finally, for evaluating the degree of consistency amongst the coders, we used the Cohen's Kappa by randomly selecting 30 articles (Cohen, 1960; Neumann, 2007; Zawacki-Richter et al., 2009). For the classification of research methods, a coding consistency of 0.799 was achieved between groups A and B. The coding consistency for classification of research area between group A and group B was 0.934 . Thus, the inter-rater reliability, being more than 0.75 , was excellent for both coding of research methods as well as research area (Fleiss, 1981; Bakeman and Gottman, 1997).

\section{Findings and analysis}

Journal-wise representation of research on ODE in India

An analysis of articles published in the selected 11 journals of distance education, revealed that out of total 2,571 articles published during the period 2010-2019, only 191 or a meagre 7.42 pertained to ODE in India (Table 1). Interestingly a majority of these articles $(68.42 \%)$ were published in the journals published from India, namely, Indian Journal of Open Learning 


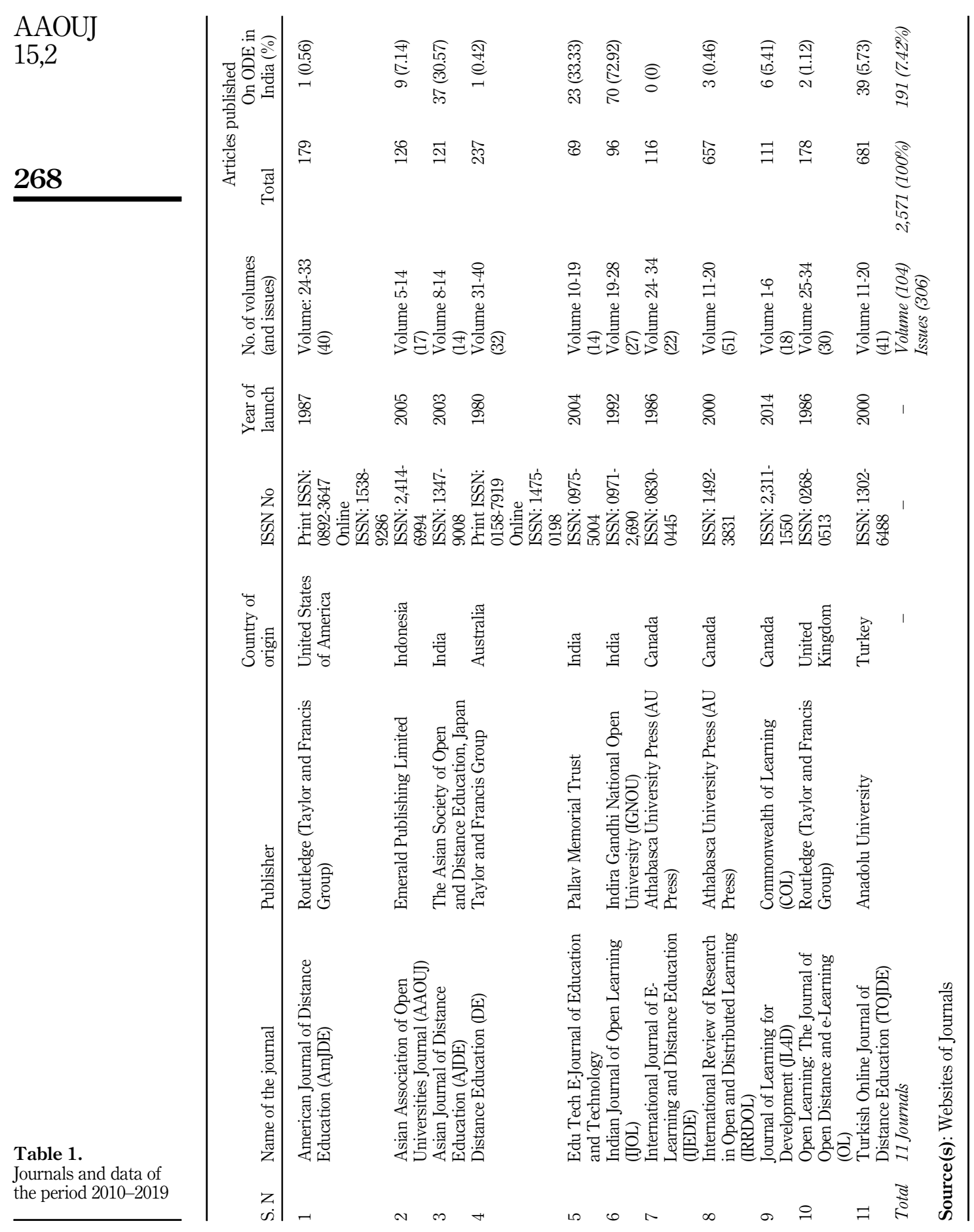


(36.65\%), Edu Tech e-Journal of Education and Technology (12.04\%) and Asian Journal of Distance Education (19.37\%). If we further add the articles published in Asian Association of Open Universities (contributing 4.71\%) published by Indonesia, and Turkish Online Journal of Distance Education (contributing 20.42\%) published by Turkey, both being Asian countries, then this share further increases to $93.55 \%$, signifying almost negligible articles on ODE on India were published by journals originating from European or American or other countries (Figure 1).

The shares of articles published on Indian ODE within respective journal was also calculated. The findings show that barring IJOL wherein articles on Indian ODE featured to the tune of $72.92 \%$, no other journal, including those published within India, contributed more than $34 \%$ on Indian ODE (EduTech $33.33 \%$ and AJDE 30.57\%) of the total articles published therein.

The year-wise distribution data of articles further showed that the share of articles on ODE in India in the overall publications was significantly low ranging from a low of $4.27 \%$ in 2014 to maximum $10.77 \%$ in 2013 (Figure 2). This low representation for sure was much below expectations from a country contributing to maximum number of ODE learners in the world. Thus, our findings coincide with the findings of other researchers including Mishra (2002).

\section{Pattern of authorship}

In order to study the authorship pattern as to whether the research on ODE in India has been solitary or collaborative, and if collaborative, then whether the collaboration was inter- or

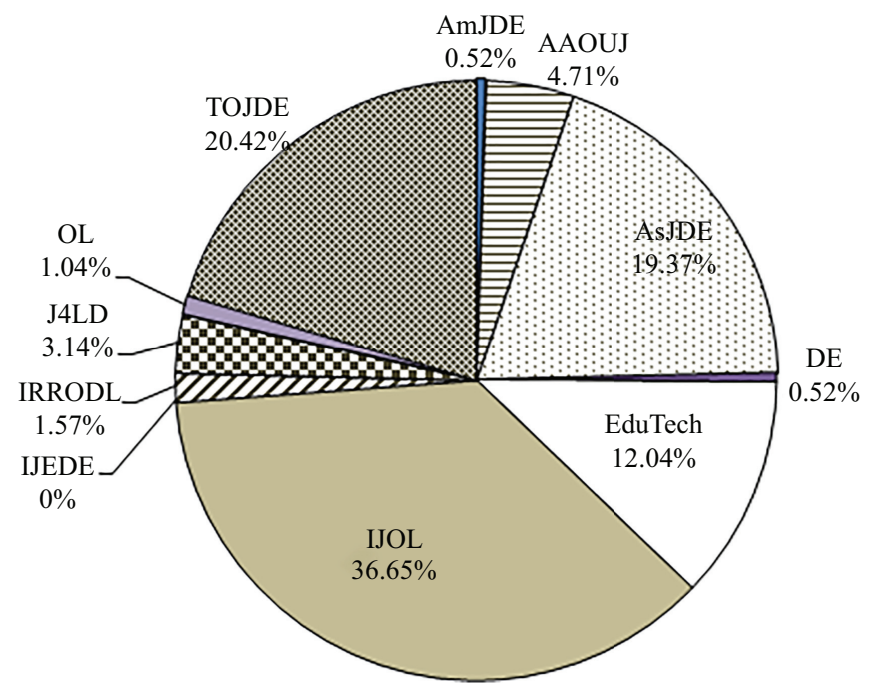

Note(s): AmJDE - American Journal of Distance Education; AAOUJ - Asian Association of Open Universities Journal; AJDE - Asian Journal of Distance Education; DE - Distance Education; EduTech - Edu Tech e-Journal of Education \& Technology; IJOL - Indian Journal of Open Learning; IJEDE - International Journal of E-Learning \& Distance Education; IRRDOL International Review of Research in Open and Distributed Learning (formerly International Review of Research in Open and Distance Learning); J4LD - Journal of Learning for Development; TOJDE - Turkish Online Journal of Distance Education
Recent trends of research in education 
AAOUJ 15,2

\section{0}

Figure 2.

Share of articles published between 2010 and 2019 on Indian ODE system across 11 journals intra-institutional, we examined the trends in authorship of the research articles over a period of 10 years across both Indian and International journals. We also tried to map the genderwise distribution of the researchers, by taking into account the gender of the principal and corresponding author. In case the principal and corresponding authors were different and belonging to different genders, then we split the score equally between the two. In respect of articles not explicitly notifying the principal or corresponding author, the gender of the first author was taken into account.

The total number of authors, who contributed the 191 articles in our study, was 333. The authorship pattern (Table 2, Figure 3) revealed that almost $97(50.78 \%)$ articles were published by single authors against $94(49.22 \%)$ articles in collaboration. Of the 94 articles published in joint authorship by 241 researchers, accounted for $29.32 \%$; and $14.66 \%$ of total 191 articles were published in joint collaboration of two and three authors, respectively. An insignificant $3.66 \%$ and $1.57 \%$ of the articles were published in joint collaboration of four and five authors, respectively. Trends further showed that except for the year 2010, when publications in joint collaboration of two authors were more than the single author publication, the single author publications always outnumbered publications by two or more authors. This trend in publication of articles on Indian ODE system was indicative of the kind of research undertaken by these authors, which was mostly system based, directed towards policy formulations or representation of learner support services data, where most of the

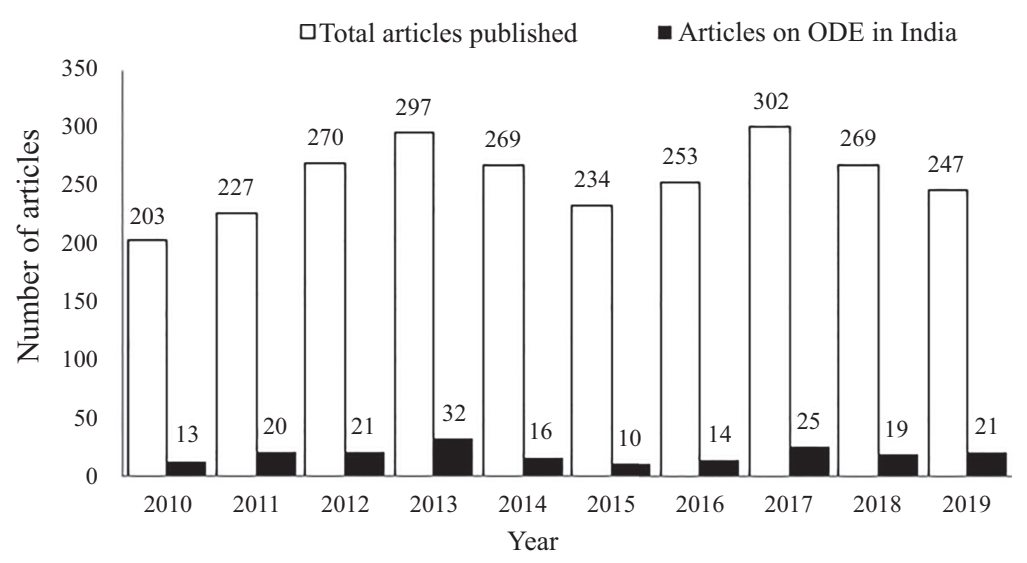

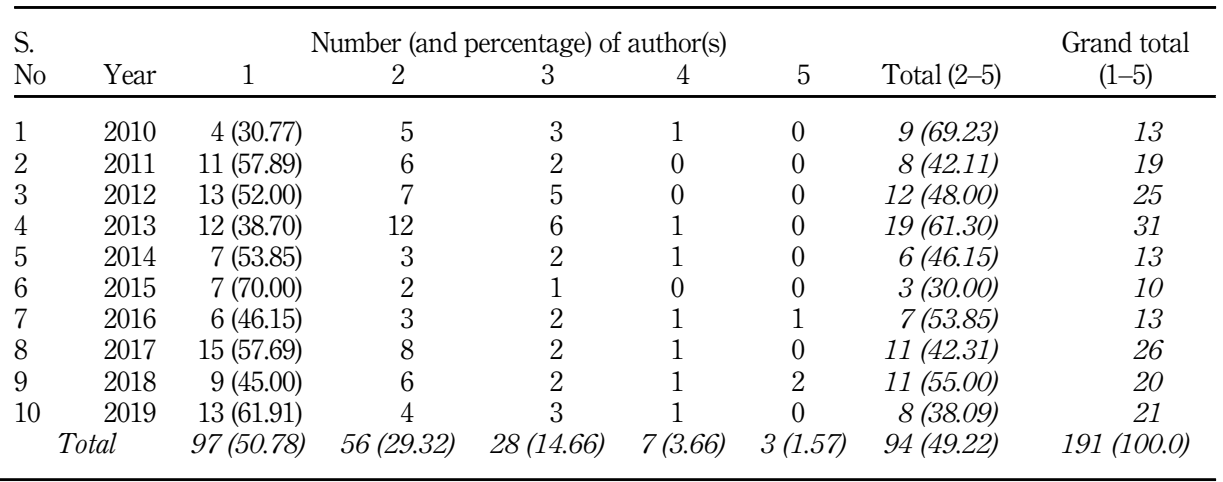




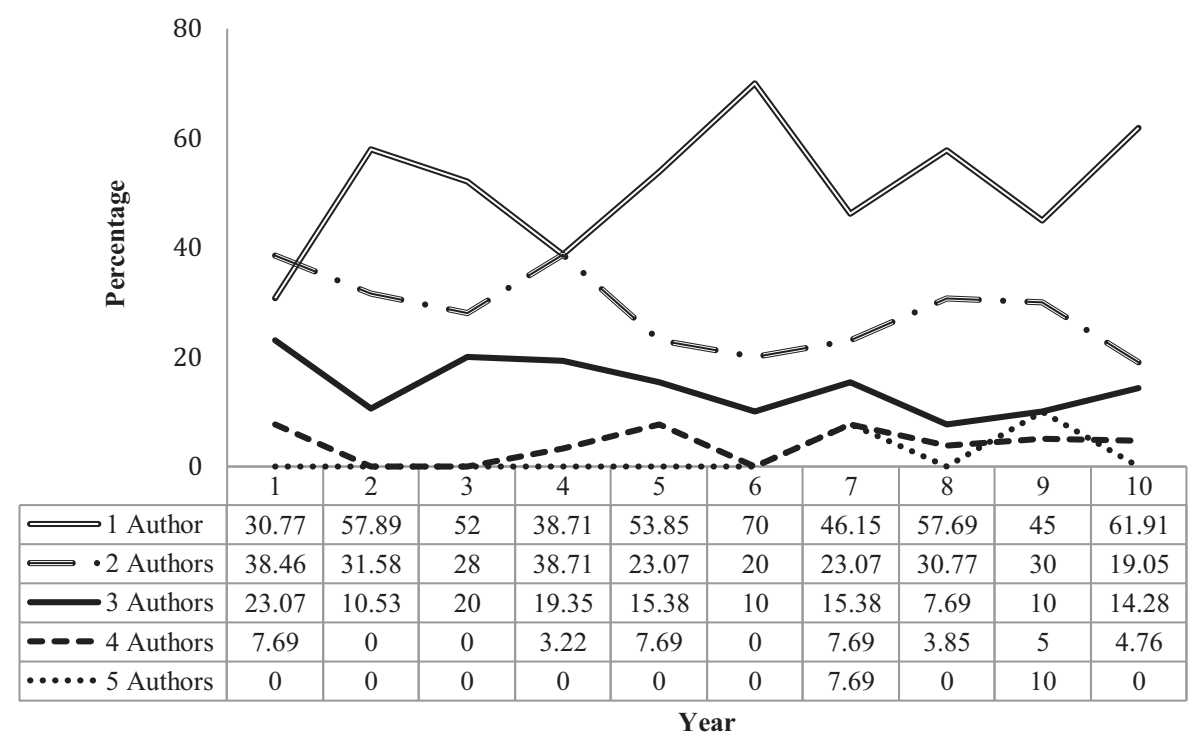

Note(s): 1-2010; 2-2011; 3-2012; 4-2013; 5-2014; 6-2015; 7-2016; 8-2017; 9-2018; 10-2019
Recent trends of research in education

Figure 3. Authorship pattern of articles published on Indian ODE

researchers carried out solitary research in their own domains. This trend was in variance with the study conducted by Zawacki-Richter et al., (2009) who in review of distance education literature published in five prominent journals of distance education between 2000 and 2008 observed a decrease in percentage of single author articles in comparison with an increasing trend towards multiple author articles. Our results of authorship pattern differed from those of Wong et al. (2016) who reported $26.9 \%$ single author articles and more than $70 \%$ multiple author articles in 2015 as against our $51 \%$ and $49 \%$ articles published by single and multiple authors, respectively.

An analysis of the institutional affiliation pattern of the 333 authors showed that almost $99 \%$ of the articles were written by authors affiliated to Indian Institutions (50 institutions) against only three authors belonging to institutions outside India, i.e. Commonwealth of Learning, Canada, Queensland University of Technology, Brisbane, Australia and University of Houston, Texas. Interestingly all the authors $(100 \%)$ in both Indian and foreign institutions were of Indian origin who had contributed articles on ODE in India (see Figure 4).

Further analysis of institutional affiliation of the authors revealed that 233 authors were affiliated to Indian Open Universities and 205 were from the Indira Gandhi National Open University alone. Thus, out of the total number of authors from Indian HEIs, $63 \%$ came from National Open University, i.e. IGNOU. The contribution of authors from State Open Universities was $8 \%$, together making the contribution of authors working in OUs to $71 \%$. Authors working at other universities (55 authors) and institutions and colleges (38 authors) accounted for the $29 \%$ of the total authors which was below expectation, considering more than 200 conventional universities and standalone institutions have been offering programmes through distance mode during this period. Our data in respect of institutional affiliation and collaboration of authors coincides with that of Wong et al. (2016) who reported that a majority of research collaboration was done between authors from the same institution. 


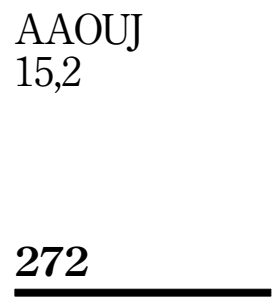

Figure 4 .

Institutional affiliation of the authors

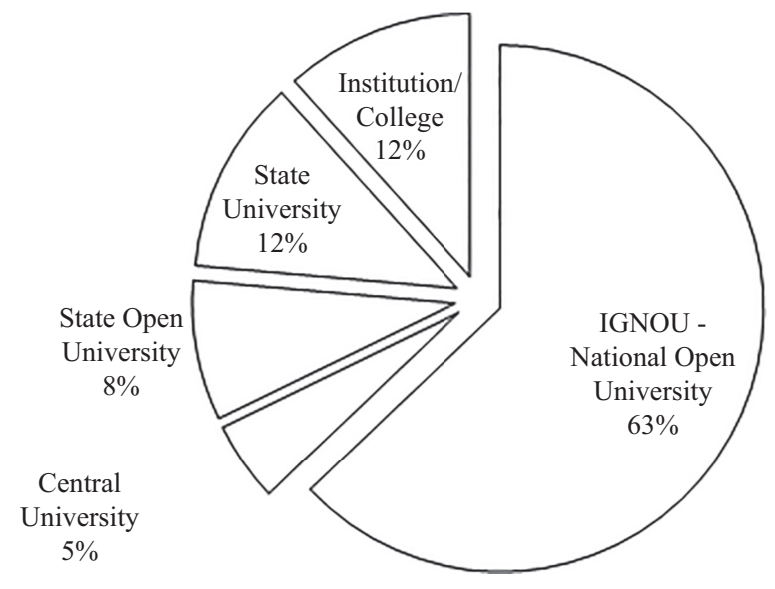

Classification of research methods

On the lines of majority of reviewers (Grant et al., 1987; Zawacki-Richter et al., 2009), we also classified research in ODE into quantitative - comprising articles based on statistical analysis of data using simple to multivariate techniques; qualitative - comprising articles using data without any statistical analysis, like case studies, interpretive and descriptive ethnographies, etc.; and mixed - comprising both qualitative and quantitative aspects.

Table 3 describes the types of research articles published on the ODE in India during the last decade (2010-2019) in the 11 journals of distance education selected for this study. The study revealed that, as already mentioned in previous sections, out of a total 191 research articles on ODE in India the majority (36.64\%) were published in IJOL, followed by TOJDE $(20.41 \%)$ and AJDE $(19.37 \%)$. Interestingly, not even a single article was published in IJEDE on Indian ODE during the last decade. The study further revealed that around $57.07 \%$ of the total 191 articles were based on empirical research whereas nearly $42.93 \%$ were theoretical in nature. On further exploration of articles based on empirical research studies, it was established that maximum $(55.05 \%)$ research studies were of mixed type, i.e. using both qualitative and quantitative methods followed by quantitative research $(25.69 \%)$ and qualitative research $(19.26 \%)$.

Our findings vary from Zawacki-Richter et al. (2009) who in their study between 2000 and 2008 comprising 695 articles, had reported $29.1 \%$ quantitative, $19.9 \%$ qualitative, and $12.9 \%$ mixed and $38.1 \%$ other studies. Our results also vary from that of Bozkurt et al. (2015) who while studying the research trends in distance education on the basis of articles published between 2009 and 2013, brought out that research studies were mostly qualitative (47\%) and quantitative (37\%), and just a few were mixed (16\%). One of the reasons for this variation is perhaps the fact that only about three-fifth of research studies on ODE in India were empirical in nature (see Figure 5).

Further analysis of data on two specific parameters, namely, (1) authorship and (2) the research methods used by the authors, (Table 3) revealed that $53.40 \%$ of the principal authors/corresponding authors were females whereas $46.60 \%$ were males. This shoulder to shoulder contribution of males and female researchers was certainly an encouraging trend, establishing an encouraging gender-wise representation of faculty members and researchers working in ODE system. With regard to the research methods employed, it was found that while quantitative methods of research were dominated by males, female researchers had majorly undertaken theoretical research methods, and in case of empirical studies they were 
Table 3.

Categorization of research methods: journal wise and gender wise 
AAOUJ

15,2

\section{4}

Figure 5.

Research methods used by the researchers

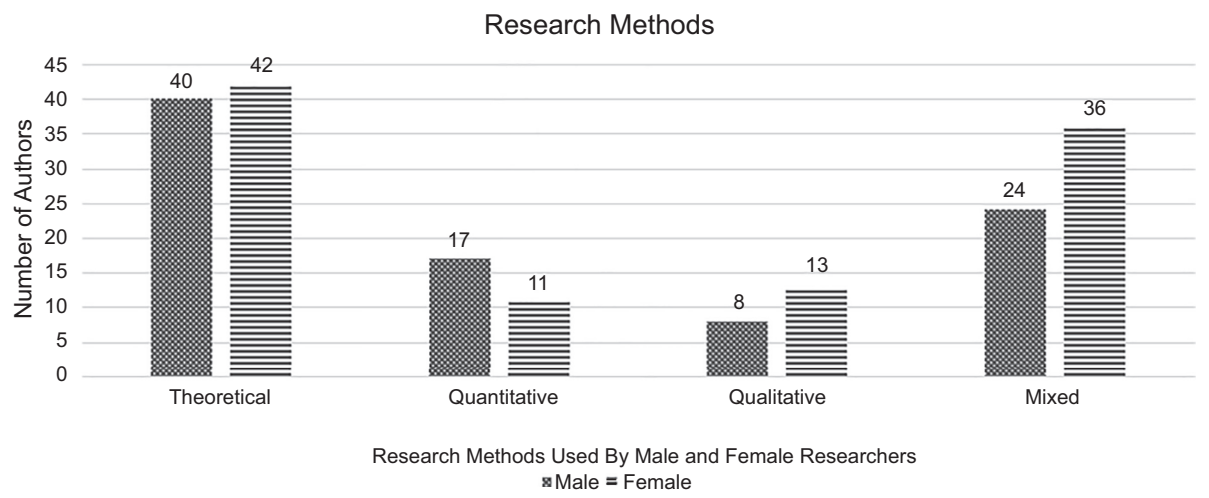

more focussed towards qualitative research as well as usage of mixed methods comprising both quantitative and qualitative methods in comparison to their male counterparts,. A journal-wise analysis has been presented in Table 3.

\section{Classification of areas of research}

The ODE system is a global phenomenon and hence every country has different research priorities based on the social, economic and geographical context, complexities and requirements. Since the authors attempted to evaluate the trend analysis of research in the ODE system in India, they found it appropriate to select those parameters that were likely to have an impact and change the direction in which ODE was likely to progress in the near future. Therefore, the seven key parameters identified and prescribed by the NAAC for assessment and accreditation of Open Universities and Directorates of Distance Education, formed the broad categories of classifying research articles published in the journals selected for present study, (mentioned at serial number 1 to 7, Table 4). In addition, since the research in the country could not be segregated and isolated from global perspectives and development in the field of ODE, the following four more areas were also added explicitly in addition to the above listed seven categories, namely, Scope, Growth and Development; Economics and Funding; Quality Assurance in ODE; and Globalization and Networking (mentioned at serial number 8 to 11, Table 4).

We thoroughly examined all the 191 articles on Indian ODE system for classifying them on the basis of research area an analysis of which has been given in Table 5, Figure 6. The data in Table 5 revealed the frequency of publications under different areas as categorized under 11 heads. A glance at the total number of publications across the broad categories of research over a period of 10 years showed that teaching, learning and evaluation comprised the highest number of articles with $36.13 \%$ of the total publications followed by articles on the curricular aspects (18.85\%); learner support and progression (14.13\%); governance, leadership and management $(9.95 \%)$; research, innovation and extension $(6.81 \%)$; scope, growth and development $(6.28 \%)$; infrastructure and learning resources $(3.14 \%)$; quality assurance in ODE (2.62\%); institutional values and best practices $(0.52 \%)$; economics and funding $(1.05 \%)$; and globalization and networking $(0.52 \%)$. Our findings somewhat coincide with the findings of Wong et al. (2016) who had reported that that "instructional design" had the largest group of research articles published in both 2005 (25.5\%) and $2015(21.4 \%)$ and a significant number of research articles were published on "learner characteristics" in $2015(14.3 \%)$.

The publication trends portrayed the skewed number of publications in some of the important areas like globalization and networking, funding and economics, institutional 


\begin{tabular}{|c|c|c|c|}
\hline Code & Theme & Description & \\
\hline 1 & Curricular aspects & $\begin{array}{l}\text { Curriculum design and development; instructional design; learning } \\
\text { outcome-based curricula; openness, flexibility and modular } \\
\text { approach; credit transfer; programme evaluation; including } \\
\text { development of skills and competencies and learner engagement }\end{array}$ & $n$ \\
\hline \multirow[t]{2}{*}{2} & \multirow[t]{2}{*}{$\begin{array}{l}\text { Teaching - learning and } \\
\text { evaluation }\end{array}$} & \multirow{2}{*}{$\begin{array}{l}\text { Pedagogy of ODE; transaction of curricula; delivery of programmes } \\
\text { through multiple media including online learning, MOOCs and OERs; } \\
\text { student evaluation both formative and summative; including learner } \\
\text { access and equity and learner characteristics, learning styles (student } \\
\text { learning) and learner diversity }\end{array}$} & 275 \\
\hline & & & \\
\hline 3 & $\begin{array}{l}\text { Research, innovations and } \\
\text { extension }\end{array}$ & $\begin{array}{l}\text { Promotion of research and innovation; extension activities; } \\
\text { consultancy and collaboration with industry, corporate sector/ } \\
\text { government sector etc. }\end{array}$ & \\
\hline 4 & $\begin{array}{l}\text { Infrastructure and learning } \\
\text { resources }\end{array}$ & $\begin{array}{l}\text { Physical and IT infrastructure, learning resources including } \\
\text { production facilities and library facility }\end{array}$ & \\
\hline 5 & $\begin{array}{l}\text { Learner support and } \\
\text { progression }\end{array}$ & $\begin{array}{l}\text { Learner support activities: promotion and publicity; student } \\
\text { registration; material dispatch; counselling and tutoring; grievance } \\
\text { redressal; student progression; placement; alumni engagement }\end{array}$ & \\
\hline 6 & $\begin{array}{l}\text { Governance, leadership and } \\
\text { management }\end{array}$ & $\begin{array}{l}\text { Vision and mission; strategic planning; governance; leadership; } \\
\text { financial management ; monitoring mechanisms for quality } \\
\text { assurance; professional development/staff development }\end{array}$ & \\
\hline 7 & $\begin{array}{l}\text { Institutional values and best } \\
\text { practices }\end{array}$ & $\begin{array}{l}\text { Institutional policy for transparency and accountability; gender } \\
\text { sensitization; disabled friendly environment; promotion of universal } \\
\text { values, national and social responsibilities; environment and green } \\
\text { initiatives }\end{array}$ & \\
\hline 8 & $\begin{array}{l}\text { Scope, growth and } \\
\text { development }\end{array}$ & $\begin{array}{l}\text { Growth and development of the ODE system in the country, region, } \\
\text { state; systemic change/disruption in the system; including impact } \\
\text { assessment }\end{array}$ & \\
\hline 9 & Economics & Costing; cost benefit analysis; funding; income and expenditure & \\
\hline 10 & Quality assurance in ODE & $\begin{array}{l}\text { Assessment and accreditation practices; quality-related issues and } \\
\text { policies; mechanisms for quality assurance }\end{array}$ & \\
\hline 11 & Globalization and networking & $\begin{array}{l}\text { Issues pertaining to globalization; networking amongst institutions, } \\
\text { etc. }\end{array}$ & $\begin{array}{r}\text { Classification of areas } \\
\text { of research }\end{array}$ \\
\hline
\end{tabular}

values and best practices, which certainly was discouraging, requiring ODE institutions in India to introspect and take measures to improve research in those areas. Taking cue from the available data, it could be inferred that probably our ODE institutions were yet to focus on areas with a global perspective. Our findings of an imbalance in the articles published across various research areas is in consonance with that of Zawacki-Richter et al. (2009) and Bozkurt et al. (2015) who had also found an imbalance between research areas as well as the fact that research on areas such as globalization and cultural aspects of ODE remain relatively scarce.

We further carried out a brief content analysis of kind of research reflected under each research area and the key focus of the articles identified under the 11 research themes/areas have been outlined area wise:

\section{(1) Curricular Aspects (36 articles)}

A large number of articles ( 36 or $18.85 \%$ ) were from this theme. There were articles on the use of electronic media for transaction of the curriculum focussing on the development of mainly cognitive skills through use of information and communication technology (ICT). Several of the articles were based on studies undertaken that used enquiry methods for eliciting response from the learners on their preferred media for instructional purposes. A few studies were on programme development processes as well as programme evaluation on lab-based programmes through distance mode, namely, geriatric medicine, physics, dietetics and food 


\section{AAOUJ \\ 15,2}

\section{6}

Table 5.

Journal-wise frequency of publication across the 11 research areas

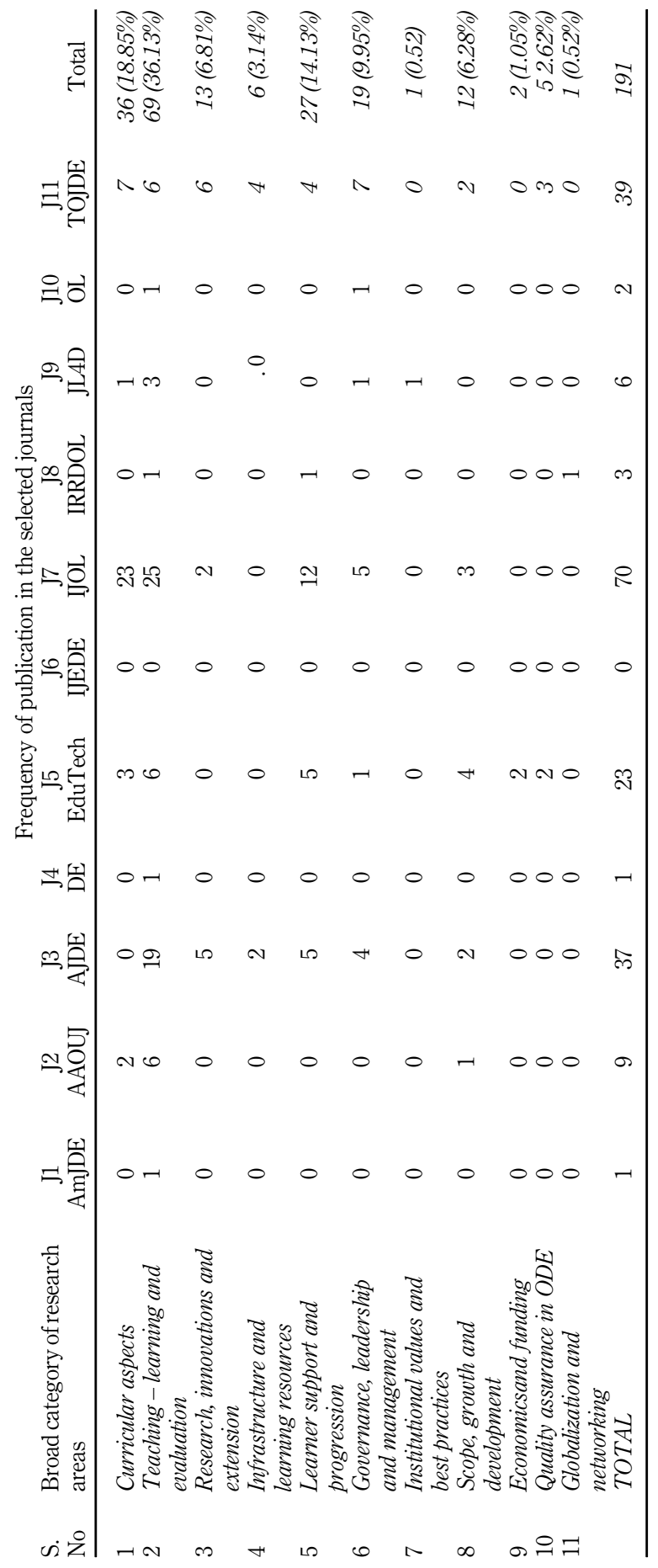




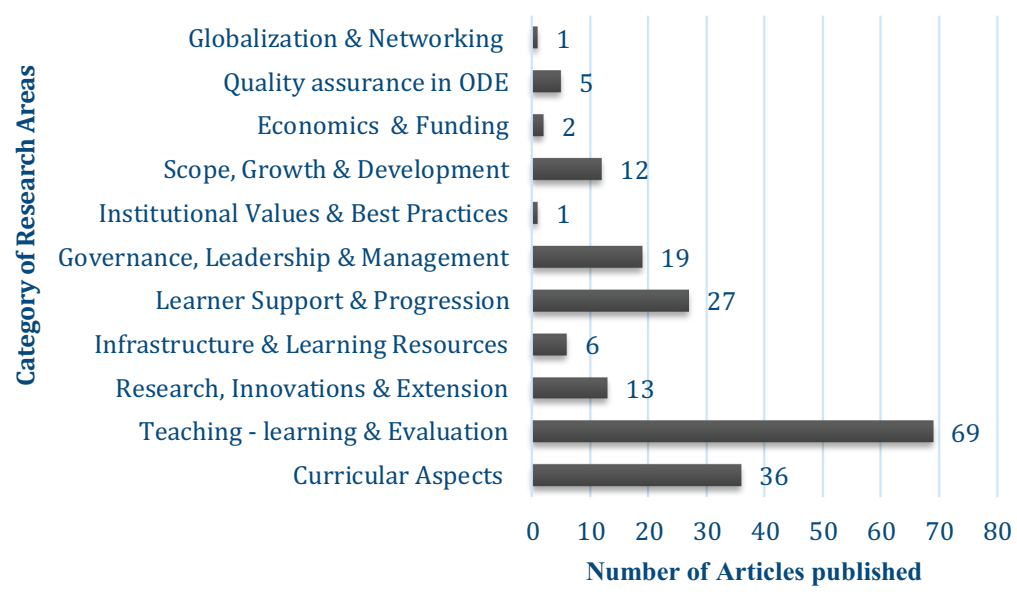

Recent trends of research in education

safety management, engineering, etc. Enhancement of employability skills of the learners through components on skill development in the curriculum design was also emphasized upon in a few articles. Even collaboration with industry for design of the skill component for smooth transition from learning to earning was suggested. A few articles were also based on need assessment studies for development of programmes.

(2) Teaching Learning and Evaluation (69 articles)

This theme represented the highest number of articles (69 or 36.13\%). However, it is worth mentioning that the articles on this theme were concentrated in two journals, namely, IJOL and AJDE. The articles have dealt comprehensively about the use of ICT interventions in ODE institutions for reaching the unreached particularly in respect of disadvantaged sections of the society for their education including jail inmates. The articles focussed on some viable models for integrating ICT in teaching-learning, student admission, library services and student evaluation. A number of articles highlighted the massive use of OER, MOOCs, cloud computing to the advantage of reaching out to heterogeneity in population and the challenges associated with them. A considerable number of articles also dealt with the MOOC initiative of India, i.e. Study Webs of Active - Learning for Young Aspiring Minds (SWAYAM). Articles had dealt with the importance of data mining and how it helped in maintenance of admission records and examination performances. The articles had also focussed on the challenges before institutions in using ICT (such as mobile applications, online learning, virtual labs, podcasting, OERs, MOOCs, etc.) with regard to their acceptability amongst learners by analysing the learners' perception towards the use of various ICT in their learning endeavours. The publication trends in this area were indicative of massive thrust by Indian ODE Institutions including OUs towards infusing technology in the teaching learning and evaluation processes, which certainly was an encouraging trend.

(3) Research, Innovations and Extension (13 articles)

The articles under this theme were devoted to innovations in the use of Web 2.0 tools in enhancing the learning experience of the distance learners, such as social networking services for reaching out to new generation learners. Some articles were specific about innovations done through collaborations with industry in the skill enhancement of the workforce; for improving agricultural practices in the farming community; for teaching foreign language programmes through ICT; initiation of the project for providing continuing education and 
AAOUJ

15,2

\section{8}

obtaining civilian degrees to armed forces; and creation of a centre for innovation for dissemination and collation of innovative practices in an ODE institution.

(4) Infrastructure and Learning Resources (6 articles)

The articles under this theme, underlined the instrumental role played by ICT to promote and facilitate learning in the distance learners and focussed on the adoption of web-based technologies and IT infrastructure by ODE institutions. Some of the articles also discussed about the role of government technical support in the delivery of ODE programmes. Case studies and best practices with regard to use of technology and their impact particularly on the functioning of OUs and on the ODE system as such were also included under this category.

(5) Learner Support and Progression (27 articles)

After first two research areas, learner support and progression attracted a good number of articles (27 or $14.1 \%$ ). The majority of the research studies under this area discussed the use and effectiveness of ICT/latest technologies in support services to improve the quality of ODE in India. Some studies were undertaken to garner the views of the learners on: the curriculum of the programme of study; effectiveness of academic counselling; their study habits; the use of ICT in programme delivery; improvement in their career prospects after completion of their programme of study and their opinion/expectations from the policy on ODE. The nature of student's grievances and queries and resolution mechanisms were also analyzed. There was also a study that compared the motivation levels of ODE learners with that of conventional learners.

(6) Governance, Leadership and Management (19 articles)

The articles under this thematic area were dedicated majorly to e-governance and management of institutions for both human resource and financial management, through the use of modern technologies. Some articles focussed on online staff development strategies for improving the effectiveness of the internal processes as well as delivery of services to the learners. Thus, the focus was on the use of ICT for bringing in the much-needed transformation of the ODE system.

(7) Institutional Values and Best Practices (1 article)

There was only one publication found under this theme. The article focussed on ODE system in India for promoting inclusive education and discussed the role of the national OU in successfully imparting education and training to socially, economically, physically and/or geographically disadvantaged, in addition to women, minorities and jail inmates.

(8) Scope, Growth and Development (12 articles)

The research studies under this theme, discussed mainly the scope of ODE in empowering the marginalized sections of the Indian society; for reaching out to the populations living in the remote and hilly regions such as the North East; a system suitable for catering to the needs of a post-industrial age; and one research study even discussed the need for the disruption in the existing system and the suggested the way forward to cope with the requirements of the digital age. There was only one impact assessment study of ODE on urban and rural distance learners.

(9) Economics and Funding (2 articles)

Both the articles have dealt with the unit cost of higher education in general and ODE in particular, focussing on the cost effectiveness of investment in higher education, comparative development cost per student in universities, different types of educational costs, including the cost analysis of academic programmes and economies of scale. 
(10) Quality Assurance in ODE (5 articles)

All the articles focussed on quality of the pedagogy through ODE and online modes. One of them focussed specifically on how to improve the quality of Teacher Education through distance mode. Also, an online model for mentoring HEIs preparing for quality assessment and accreditation was included under the theme quality assurance.

(11) Globalization and Networking (1 article)

The sole article explored the possibilities of sharing of academic resources through the adoption of an institutional policy for OERs and MOOCs as part of the global open access and open education movements and networking amongst educational institutions.

\section{Potential areas}

Themes like "Governance, Leadership and Management" and "Research, Innovations and Extension" were moderately explored by researchers during last decade. It has further been observed that "Globalization and Networking" thematic area was the least preferred by the researchers for the purpose of research as only one research article was written in this area. Besides this, "Economics and Funding" theme was not touched upon significantly with only two articles found in the journals, though the inflow and outflow of monetary resources is the backbone of any system and considerably required to plan for future endeavours and hence, needs exhaustive research. For any institution to flourish and mark its significance, both quantity along with quality matters, however, without quality, numbers may not sustain for long. Keeping this fact in mind, it is pertinent to mention here that a theme like "Quality Assurance in ODE" was not considered a priority area for research as only five articles were published in the said area. Another area, namely "Institutional Values and Best Practices" was also a neglected area with only one article belonging to this particular theme. Apart from above-mentioned thematic areas, "Infrastructure and Learning Resources" which is an important area reflecting the development of an institution, barely six articles were articulated on this theme, in the last 10 years.

Further, the OUs and DMUs over the years have evolved and have established practices that have become their recognizable attributes or distinctions. These special attributes need to be studied and extensively published so that the model can be replicated or modified as per the needs of other universities. Also, NAAC has established the benchmarks to maintain the standards of quality in the ODE system. New areas of importance have emerged which need to be explored and investigated such as empowerment and inclusion; environmental consciousness and sustainability, human values and professional ethics; transparency in financial, academic and administrative functioning; responsiveness towards learners; accountability and transparency; e-governance; technology enabled learner support; etc. (NAAC, 2019).

\section{Measures for strengthening system-based research}

The journey of distance education research, not only in India but also in Asia, has been staggered in terms of its outcome and application for development of the ODE system. The SCImago Institutions Rankings (SIR) (2020) which ranks academic and research-related institutions based on research performance, innovation outputs and societal impact measured by their web visibility reveals that only five OUs figure in the portal consisting of 3898 HEIs, namely, The Open University of UK (United Kingdom) ranked 795; the Open University Netherlands (Netherlands)1658 ; the Open University of Israel (Israel) 2,144; Anadolu University (Turkey) 2,328 and Hellenic Open University (Greece) 3105. Interestingly, none of the Asian Open Universities featured in the list. This scenario is palpable since the 
AAOUJ

15,2

280
ODE institutions particularly in India need to travel extra miles and take their endeavours towards making their research base strong. It is not that research is not going on in Indian Open Universities; rather, perhaps it is the non-publication by Indian researchers in international journals that has projected this picture. A university is known by the research it indulges in. Research is the gateway to investigate and identify the gaps and infuse new ideas into the system. The following measures adopted by ODE institutions will strengthen research on ODE system and yield the desired results.

\section{Dedicated research centres}

Instances show that wherever the universities have their dedicated research wing, it has yielded results. The Open University UK has a long tradition of carrying out research into learning and learning analytics, applied research into the use of new technologies through its Institute of Educational Technology established in 1970, for modelling the design of learning at the Open University. In this regard, the dedicated research departments on ODE supported by ODE institutions like International Research Foundation, Deakin University, Australia; the American Centre for the Study of Distance Education at College of Education at Pennsylvania State University, USA; Canadian Institute of Distance Education and Research at Athabasca University; need a special mention. Amongst the dedicated research units in Asia: Staff Training and Research Institute of Distance Education (STRIDE) in IGNOU; Prof. G. Ram Reddy Research Academy of Distance Education (GRADE) in BRAOU; Institute of Distance Education in Korean National Open University and Centre for Research in Distance and Adult Learning (CRIDAL) (renamed as the Institute for Research in Open and Innovative Education) in Open University of Hong Kong; are also independent units devoted for research in distance education (Gaba, 2007).

\section{Institutional policy on system-based research}

A critical analysis through the present study also poses a formidable question. Where have we gone wrong? Maybe it is the absence of a robust institutional policy which has prevented or impeded the research temperament in the OUs and Dual Mode Universities. An institutional policy will put the faculty on the path to undertake both discipline-based and system-based research. System-based research needs to be encouraged by ODE institutions to constantly review the existing practices and bring about qualitative improvements in the functioning of the system. ODE being a dynamic system adopting and adapting to the new technological advancements, needs to be constantly changing as per the requirements of the target groups it serves. However, all systemic changes should be informed decisions embedded in solid research. This will reflect on the commitment of the institution towards quality assurance.

\section{Funding of research activities}

The financial health of the OUs, further limits the promotion of research. The 14 State Open Universities in India, contributing significantly to the higher educational aspirants in the country have immense potential. They need adequate financial resources for research, capacity building activities, incentive for research and most pertinently, government support. Therefore, the onus is on the government as well as ODE institutions to encourage research at the university, both systemic and discipline based. In India, where the government targets towards increasing the GER, thrust should be on empowering those universities/institutions particularly which are offering education at affordable costs to the disadvantaged sections of the society.

\section{Collaboration with industry}

Collaborative research activities with industries, is one of the important aspects to be integrated in the institutional policy of an ODE institution. Besides the institutional policy, 
what is important is the need to conduct multidimensional research. It is worth mentioning Borje Holmberg's distinction between endogenous and exogenous research. Endogenous research looks at work done within distance education, such as studying the methods, systems, media, etc. Exogenous research focusses on the economic, demographic, cultural, social and political contexts of ODE. (Kanwar and Balasubramanian, 2014). "Institutions that generate knowledge increasingly play a role in the networks of relations among the key actors: University (Science), Industry (Business), and Government (Governance). The governments create a system that defines, regulates an innovation process of enterprises. Conceptualization of this system is provided by a three-dimensional vector space called Triple Helix of university-industry-government model. Each of the three actors, universityindustry-government, participates in Wealth generation" (Vaivode, 2015).

\section{Conclusion}

The extensive review done by the authors reveals that in spite of having access to online journals, the presence of research studies on ODE on India in foreign journals is scanty; slightly better represented in the Asian journals and Indian journals. The quantum of research is not proportionate to the number of faculty members working in the ODE system of India and the large number of learners that it serves, which is a matter of concern. Research on ODE in India, in absence of a strong institutional policy for research in the premier universities offering programmes through distance mode, faces a number of challenges that need to be addressed. Even after nearly six decades of the existence of Dual Mode Universities, and nearly four decades of OUs in India, the institutional best practices pertaining to ODE have not generated required attention perhaps due to lack of networking and collaborative ventures amongst ODE institutions as well as fewer number of publications in international journals. However with the emphasis on research output of the teachers working in HEIs, including Open Universities and Directorates of Distance, Education, which is an essential and important parameter for accreditation of the institution, its national ranking, as well as a mandatory requirement for career advancement of teachers, the research is picking up a fast rate. This study will provide valuable insights and certainly act as an ignition to motivate ODE practitioners, working at Open Universities and Dual Mode Universities, to take the research on ODE forward.

In fact, for any system to grow its periodic systemic review is essential, more so for the ODE system, being a dynamic and innovative system that constantly keeps on evolving, through the adoption of newer technologies for improving curricular aspects, teachinglearning and evaluation and learner support services to its dispersed learners. The ODE system in India requires more empirical research to be undertaken periodically. The research outcomes need to be ploughed back into the system for its betterment. Thus, the missing links in distance education research which are yet to be addressed in its entirety needs to be systematic, professional and action based.

\section{References}

Bakeman, R. and Gottman, J.M. (1997), Observing Interaction - an Introduction to Sequential Analysis, Cambridge University Press, Cambridge.

Bewley, D. (2008), "Australian and South pacific external studies association: ODLAA's regional predecessor", Distance Education, Vol. 29 No. 1, pp. 19-37, available at: https://www.tandfonline. com/doi/abs/10.1080/01587910802004829 (accessed 8 June 2020).

Bozkurt, A., Akgun-Ozbek, E., Yilmazel, S., Erdogdu, E., Ucar, H., Guler, E., Sezgin, S., Karadeniz, A., Sen-Ersoy, N., Goksel-Canbek, N., Dincer, G.D., Ari, S. and Aydin, C.H. (2015), "Trends in
Recent trends of research in education 
AAOUJ 15,2

\section{2}

distance education research: a content analysis of journals 2009-2013", International Review of Research in Open and Distributed Learning, Vol. 16 No. 1, pp. 330-363.

Cohen, J. (1960), "A coefficient of agreement for nominal scales", Educational and Psychological Measurement, Vol. 20, pp. 37-46.

Fleiss, J.L. (1981), Statistical Methods for Rates and Proportions, Wiley, New York, NY.

Gaba, A. (2007), "Research in open and distance education: status and policy issue", University News, Vol. 45 No. 16, pp. 8-16.

Government of India (2010), "UGC regulations for minimum qualifications for appointment of teachers and other academic staff at universities and colleges and measures for maintenance of standards in higher education, 2010, (18th September) Gazette of India, extraordinary part III, section -4", available at: https://www.ugc.ac.in/oldpdf/regulations (accessed 10 June 2020).

Government of India (2017), "University grants commission (open and distance learning) regulations, 2017, (23rd June) Gazette of India, extraordinary part III, section -4", available at: https://www. google.com/url? sa $=$ tandsource $=$ webandrct $=$ jandurl $=$ https://ugc.ac.in/oldpdf/regulations/ distance $\% 2520$ education $\% 2520$ regulations.pdfandved = 2ahUKEwic4bmOoujoAhXFV3 wKHUUyD-UQFjACegQIBRACandusg=AOvVaw2813ijhz7MGoRj-j7n1faK (accessed 12 April 2020).

Government of India (2018), "UGC Regulations for minimum qualifications for appointment of teachers and other academic staff at universities and Colleges and measures for maintenance of standards in higher education, 2018, (18th july) Gazette of India, extraordinary Part III, section-4", available at: https://www.ugc.ac.in/pdfnews/4033931_UGC-Regulation_min_Qualification_ Jul2018.pdf (accessed 10 June 2020).

Grant, L., Ward, K.B. and Rong, X.L. (1987), "Is there an association between gender and methods in sociological research?”, American Sociological Review, Vol. 52, pp. 856-862.

Gupta, A.K. and Arun, R. (1986), "Survey of recent Indian writings in distance education”, Distance Education: An International Journal, Vol. 1 No. 2, pp. 20-26.

Holmberg, B. (1986), “A discipline of distance education”, Athabasca University Press, The Journal of Distance Education / Revue de l'education Distance, Vol. 1 No. 1, available at: http://www.ijede. ca/index.php/jde/article/view/306 (accessed 8 June 2020).

Kanwar, A. and Balasubramanian, K. (2014), "Advancing research in ODL: where are the missing links?", opening keynote address", Proceedings of the 28th Annual Conference of the Asian Association of Open Universities, Hong Kong, China, 28 October 2014, available at: http:// aaou2014.ouhk.edu.hk/e-keynote.html (accessed 10 June 2020).

Mishra, S. (1997), "A critical analysis of periodical literature in distance education”, Indian Journal of Open Learning, Vol. 6 Nos 1 and 2, pp. 39-53.

Mishra, S. (2002), "Ten years of Indian journal of open learning”, Indian Journal of Open Learning, Vol. 11 No. 2, pp. 279-290.

Moore, M. (2016), "Thirty years later: Self-directed learning and distance education - in retrospect", The Journal of Distance Education / Revue de l'ducation Distance, Vol. 31 No. 2, available at: https://www.learntechlib.org/p/183673/ (accessed 8 June 2020).

NAAC (2019), NAAC Institutional Accreditation Manual: Self Study Report Open University, NAAC, Bangalore, available at: http:/www.naac.gov.in/images/docs/Manuals/OpenUniversity-Manual11-12-2019.pdfhttp://www.naac.gov.in/images/docs/Manuals/Draft-Dual-Mode-UniversityManual.pdf (accessed 6 June 2020).

Neumann, W.L. (2007), Social Research Methods: Qualitative and Quantitative Approaches, Pearson, Boston.

Panda, S. (1992), "Distance educational research in India: Stock-taking, concerns and prospects", Distance Education, Vol. 13 No. 2, pp. 309-326.

Panda, S.K., Satyanarayana, P. and Sharma, R.C. (1996), Open and Distance Education Research: Analysis and Annotation, IDEA, Kakatiya University, Warangal. 
Peters, O. (1983), "Distance teaching and industrial production: a comparative reinterpretation in outline”, in Sewart, D., Keegan, D. and Holmberg, B. (Eds), Distance Education. International Perspectives, Croom Helm, London, pp. 95-113.

Satyanarayana, P. and Mantha, L. (2018), "Survey of research in Indian distance education", Asian Journal of Distance Education, Vol. 13 No. 2, pp. 17-145, available at: http://www.asianjde.org/ ojs/index.php/AsianJDE/article/view/275 (accessed 9 June 2020).

SCImago, S.I.R.(2020), SCImago Institutions Rankings, [Portal], available at: https://www.scimagoir. com/rankings.php?sector $=$ Higher\%20educ (accessed 15 June 2020).

Srivastava, M. (2012), Mapping Research in ODL, Chapter 5 in Open Universities: India's Answer to Challenges in Higher Education, Vikas Publishing House Pvt Ltd., New Delhi, pp. 85-104.

Tripathi, M. and Kanungo, N. (2010), "Information use pattern of researchers in open and distance education: an analysis of citations of Indian journal of open learning”, Indian Journal of Open Learning, Vol. 19 No. 3, pp. 183-198.

University Grants Commission (2019), Annual Report 2018-19, University Grants Commission, New Delhi, available at: https://www.ugc.ac.in/pdfnews/3060779_UGC-ANNUAL-REPORTENGLISH-2018-19.pdf (accessed 2 May 2020).

Vaivode, I. (2015), "Triple Helix model of university-industry-government cooperation in the context of uncertainties”, Procedia - Social and Behavioral Sciences, Vol. 213, pp. 1063-1067, available at: https://ortus.rtu.lv/science/en/publications/24060-Triple+Helix+Model+of+University $\%$ E2\% $80 \% 93$ Industry $\%$ E2\% $\% 0 \% 93$ Government+Cooperation +in+the+Context+of +Uncertainties (accessed 14 June 2020).

Wong, Y.Y., Zeng, J. and Ho, C.K. (2016), "Trends in open and distance learning research: 2005 vs 2015”, Asian Association of Open Universities Journal, Vol. 11 No. 2, pp. 216-227.

Zawacki-Richter, O., Backer, E.M. and Vogt, S. (2009), "Review of distance education research (20002008): analysis of research areas, methods, and authorship patterns", International Review of Research in Open and Distance Learning, Vol. 10 No. 6, pp. 21-30, available at: https://files.eric. ed.gov/fulltext/EJ869423.pdf (accessed 11 June 2020).

\section{Corresponding author}

Manjulika Srivastava can be contacted at: manjulika@ignou.ac.in
Recent trends of research in education

For instructions on how to order reprints of this article, please visit our website:

www.emeraldgrouppublishing.com/licensing/reprints.htm

Or contact us for further details: permissions@emeraldinsight.com 